\title{
How does Africa's most hunted bat vary across the continent? Population traits of the straw-coloured fruit bat (Eidolon helvum) and its interactions with humans
}

\author{
Alison J. Peel ${ }^{1,2,3,18}$, James L. N. Wood ${ }^{1}$, Kate S. Baker ${ }^{1,2}$, Andrew C. Breed ${ }^{4}$, Arlindo de Carvalho ${ }^{5}$, \\ Andrés Fernández-Loras ${ }^{2}$, Harrison Sadiki Gabrieli ${ }^{6}$, GuY-Crispin Gembu ${ }^{7}$, Victor A. KaKenGi ${ }^{8}$, \\ Potiphar M. Kaliba ${ }^{9}$, Robert M. Kityo ${ }^{10}$, Tiziana Lembo ${ }^{11}$, Fidel Esono Mba ${ }^{12}$, Daniel Ramos ${ }^{13}$, \\ IÑaki RodrigueZ-Prieto ${ }^{14}$, Richard SuU-Ire ${ }^{15,16}$, Andrew A. Cunningham ${ }^{2}$, and David T. S. Hayman ${ }^{1,2,17}$
}

\author{
${ }^{1}$ Department of Veterinary Medicine, University of Cambridge, Cambridge, CB3 OES, United Kingdom \\ ${ }^{2}$ Institute of Zoology, Zoological Society of London, Regent's Park, London, NW1 4RY, United Kingdom \\ ${ }^{3}$ Environmental Futures Research Institute, Griffith University, Brisbane, Queensland, 4111, Australia \\ ${ }^{4}$ Animal and Plant Health Agency (APHA), Addlestone, Surrey, KT15 3NB, United Kingdom \\ ${ }^{5}$ Direção Geral de Ambiente, Avenida Kwame Krhuma-Caixa Postal 1023, São Tomé, São Tomé e Príncipe \\ ${ }^{6}$ Tanzania Veterinary Laboratory Agency (TVLA), Ministry of Livestock Development and Fisheries (MLDF), \\ P.O. Box 1026, Tanga, Tanzania \\ ${ }^{7}$ Faculté des Sciences, Université de Kisangani, Kisangani, République Démocratique du Congo \\ ${ }^{8}$ Tanzania Wildlife Research Institute, Box 661, Arusha, Tanzania \\ ${ }^{9}$ Museums of Malawi, P.O. Box 30360, Chichiri, Blantyre 3, Malawi \\ ${ }^{10}$ College of Natural Sciences, School of BioSciences, Department of Biological Sciences. Makerere University, \\ P.O. Box 7062, Kampala, Uganda \\ ${ }^{11}$ Institute of Biodiversity, Animal Health and Comparative Medicine, College of Medical, Veterinary and Life Sciences, \\ University of Glasgow, Graham Kerr Building, Glasgow, G12 8QQ, Scotland \\ ${ }^{12}$ Instituto Nacional de Desarrollo Forestal y Manejo del Sistema de Áreas Protegidas (INDEFOR-AP), \\ Calle Jesús Bakale S/N, Bata, Equatorial Guinea \\ ${ }^{13}$ Parque Natural do Príncipe, Avenida Amilcar Cabral, Cidade de Santo António, Ilha do Príncipe, \\ São Tomé e Príncipe \\ ${ }^{14}$ Department of Evolutionary Ecology, Museo Nacional de Ciencias Naturales, CSIC 28006 Madrid, Spain \\ ${ }^{15}$ Wildlife Division, Ghana Forestry Commission, Accra, Ghana \\ ${ }^{16}$ Faculty of Animal Biology and Conservation Science, University of Ghana, Box LG 571, Legon, Accra, Ghana \\ ${ }^{17}$ Molecular Epidemiology and Public Health Laboratory, Hopkirk Research Institute, Massey University, \\ Private Bag, 11 222, Palmerston North 4442, New Zealand \\ ${ }^{18}$ Corresponding author: E-mail: alisonpeel@gmail.com
}

\begin{abstract}
The straw-coloured fruit bat, Eidolon helvum, is a common and conspicuous migratory species, with an extensive distribution across sub-Saharan Africa, yet hunting and habitat loss are thought to be resulting in decline in some areas. Eidolon helvum is also a known reservoir for potentially zoonotic viruses. Despite E. helvum's importance, ecological and behavioural traits are poorly described for this species. Here we present extensive data on the distribution, migration patterns, roost size, age and sex composition of 29 E. helvum roosts from nine countries across tropical Africa, including roosts not previously described in the literature. Roost age and sex composition were dependent on timing of sampling relative to the annual birth pulse. Rather than a single 'breeding season' as is frequently reported for this species, regional asynchrony of reproductive timing was observed across study sites (with birth pulses variably starting in March, April, September, November or December). Considered together with its genetic panmixia, we conclude that the species has a fluid, fission-fusion social structure, resulting in different roost 'types' at different times of the year relative to seasonal reproduction. Bat-human interactions also varied across the species' geographical range. In the absence of significant hunting, large urban colonies were generally tolerated, yet in regions with high hunting pressure, bats tended to roost in remote or protected sites. The extensive quantitative and qualitative data presented in this manuscript are also valuable for a wide range of studies and provide an historical snapshot as its populations become increasingly threatened.
\end{abstract}

Key words: age composition, demography, fission-fusion, hunting, straw-coloured fruit bat 


\section{INTRODUCTION}

"In Eidolon helvum, which has the widest distribution and is also the greatest traveller among African fruit-bats" (Lang and Chapin, 1917a: 482). "We are not able to ... show beyond a doubt that large migrations take place at definite seasons. ... It is nevertheless certain that immense numbers of Eidolon helvum journey about irregularly and then become abundant in regions from which they were previously absent" (Lang and Chapin, 1917b: 500).

Most of the few ecological studies on strawcoloured fruit bats (Eidolon helvum (Kerr, 1792), Order Chiroptera, Family Pteropodidae) expand on hypotheses first put forward almost 100 years ago by Lang and Chapin $(1917 a, 1917 b$; Supplementary Text 1) based on a 6-year study undertaken in the Congo basin. Lang and Chapin $(1917 a, 1917 b)$ hypothesised that $E$. helvum undertook seasonal migrations across the continent to exploit changes in resource availability, that its body form made it well suited to long distance flight and that its significance as a seed disperser was likely greater than that of birds or monkeys. While it is a common and conspicuous species, and its migratory capacity is undisputed, features such as its high mobility (both in daily foraging and seasonal migrations), large roost sizes (sometimes numbering in the millions, precluding accurate population size estimation and longitudinal study of individuals) and nocturnal activity have presented challenges to subsequent studies aimed at understanding the extent, underlying drivers and significance of its long distance migrations.

The species has been recorded across most of sub-Saharan Africa (Fig. 1 - DeFrees and Wilson, 1988), yet the exact species distribution is unclear. While a central equatorial breeding zone and a peripheral migratory zone have been proposed (Kingdon, 1974; DeFrees and Wilson, 1988), comprehensive data are lacking and Bergmans (1990) suggested a more intricate geographical distribution. Recent genetic analyses demonstrated high connectivity across the continent (Peel et al., 2013) and as such, E. helvum likely comprises aggregated, mobile populations across a connected, rather than continuous, landscape. In addition to its widespread continental distribution, E. helvum populations exist on a small number of offshore islands, including those in the Gulf of Guinea (Juste et al., 2000), and off the Tanzanian coast (Hayman and Hill, 1971). Of the four main islands in the Gulf of Guinea, Bioko was previously connected to the mainland via a land bridge (and is still within daily foraging distances for E. helvum (Richter and Cumming, 2008), while Príncipe, São Tomé and Annobón were formed independently in isolation. Genetic studies have shown that E. helvum on Bioko comprise part of the panmictic continental population, whereas individuals on the other three islands are genetically distinct from one another and from the continental population (Peel et al., 2013).

As is typical for many bat species, accurate estimates of E. helvum roost and total population sizes are often unfeasible, for example, due to high density of roosting, enormous roost sizes, a tendency to roost high in tree canopies and high daily movement among roosts. No widespread population estimates have been performed. However, reliable counts have been obtained for some roosts (Perpetra and Kityo, 2009; Hayman et al., 2012; Fahr et al., 2015). Significant population declines in some regions, believed to be a result of habitat loss and hunting for food and medicine (Sodeinde and Soewu, 1999; Mickleburgh et al., 2009; Perpetra and Kityo, 2009) have contributed to the recent IUCN red list classification of E. helvum as 'Near Threatened' (Mickleburgh et al., 2008). Eidolon helvum is consumed most frequently in West and Central Africa, where it has been identified as the most heavily hunted bat for bushmeat (Mickleburgh et al., 2009; Kamins et al., 2011; Niamien et al., 2015). Given that a species' potential harvesting capacity is largely determined by its underlying demographic processes (including population size, reproductive and survival rates) (Williams et al., 2002), demographic studies are paramount to properly assessing hunting sustainability.

In this paper we examine E. helvum morphology, the size, seasonality and demography of $E$. helvum roosts across its continental and island distribution and the nature of bat-human interactions occurring at each roost using data from a variety of studies. These data provide further understanding of this species' ecology, demography and response to hunting, valuable for a wide range of studies. For example, as explored further elsewhere (Hayman and Peel, 2016), factors such as a species' life history strategy, its population status, individual animal movements, the seasonal timing of the harvest, and heterogeneity in individual's susceptibility to harvest determine a population's response to harvesting pressure (Sandercock et al., 2011). 


\section{Materials AND Methods}

\section{Capture and Data Collection}

The methods described here are documented in greater detail in prior publications, particularly in Peel et al. (2016), which is an open-access data descriptor manuscript that accompanies and facilitates interpretation and future use of the data associated with this manuscript (deposited in the online data repository, Dryad: doi:10.5061/dryad.2fp34).

Sampling locations comprised 13 E. helvum roosting sites in continental Africa, and 14 in the four main islands in the Gulf of Guinea (Fig. 1, described in detail in Table 1). Repeated sampling was conducted in Ghana, Tanzania and Annobón. All fieldwork was undertaken under permits granted by national and local authorities (listed in Acknowledgements) and under ethics approval from the Zoological Society of London Ethics
Committee (WLE/0489 and WLE/0467), using field protocols which followed ASM guidelines (Sikes et al., 2011). Mist nets $(6-18 \mathrm{~m} ; 38 \mathrm{~mm})$ were the primary capture method, either as bats departed the roost site at dusk, or returned at dawn. Bats were held in individual cloth bags until processing under manual restraint.

Data collected included morphometric (forearm length, body mass) and demographic details (age class, sex, reproductive status). Female reproductive status was assigned as non-reproductive, pregnant, or lactating, as previously described (Peel et al., 2016). The phase in the reproductive cycle (i.e. the time in months between the sampling date and the beginning of the last birthing season) was estimated based on published data and the pregnancy status of females (foetal size, assuming a true gestation period of four months (Mutere, 1965)) or degree of juvenile development during sampling.

Age was assessed by morphological characteristics as described in Peel et al. (2016) and all individuals were placed

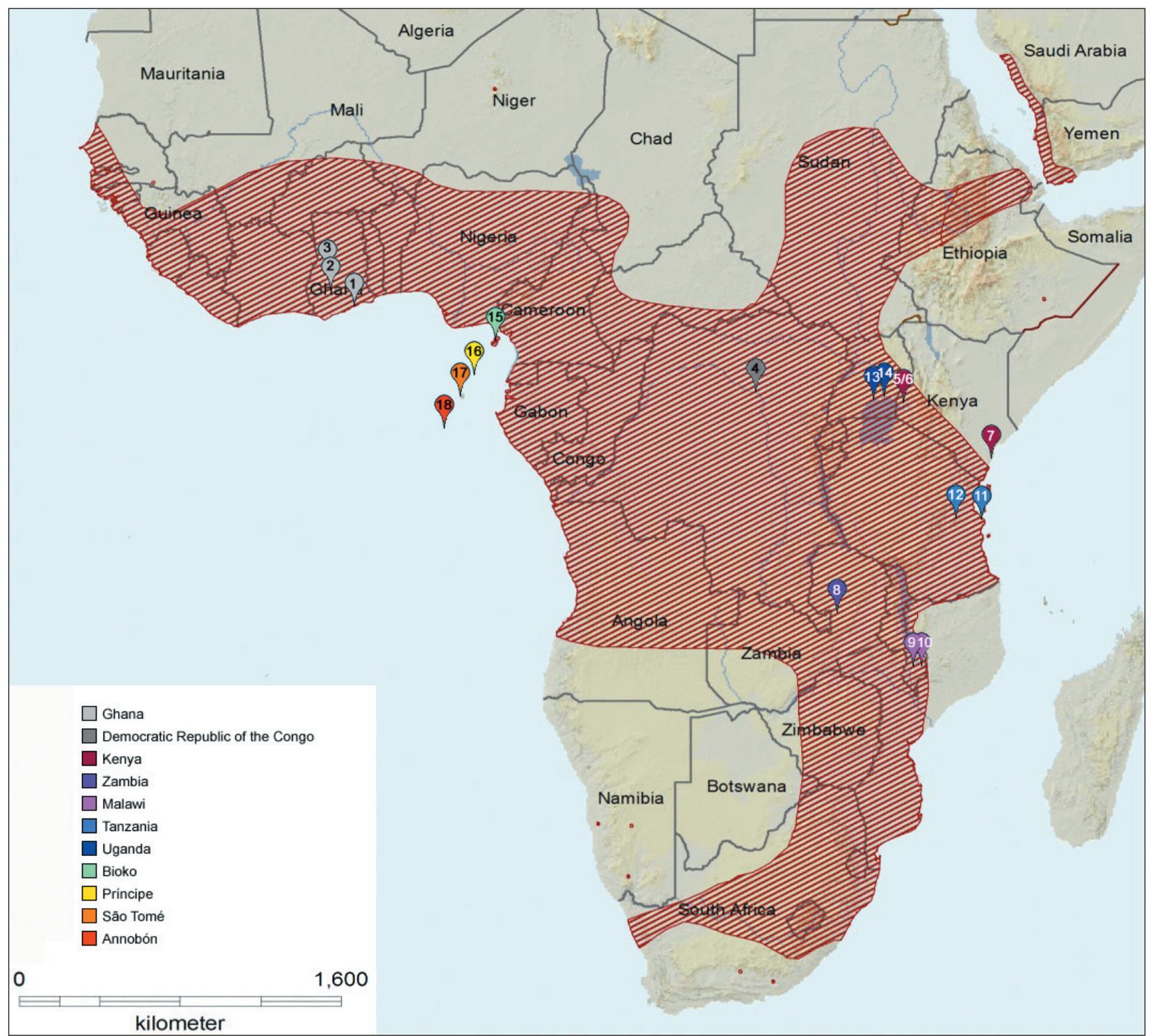

FIG. 1. Eidolon helvum sampling locations. Shading represents the distribution range of E. helvum. Sampling locations are numbered as in Table 1. Adapted from Mickleburgh et al. (2008) and Peel et al. (2013) 


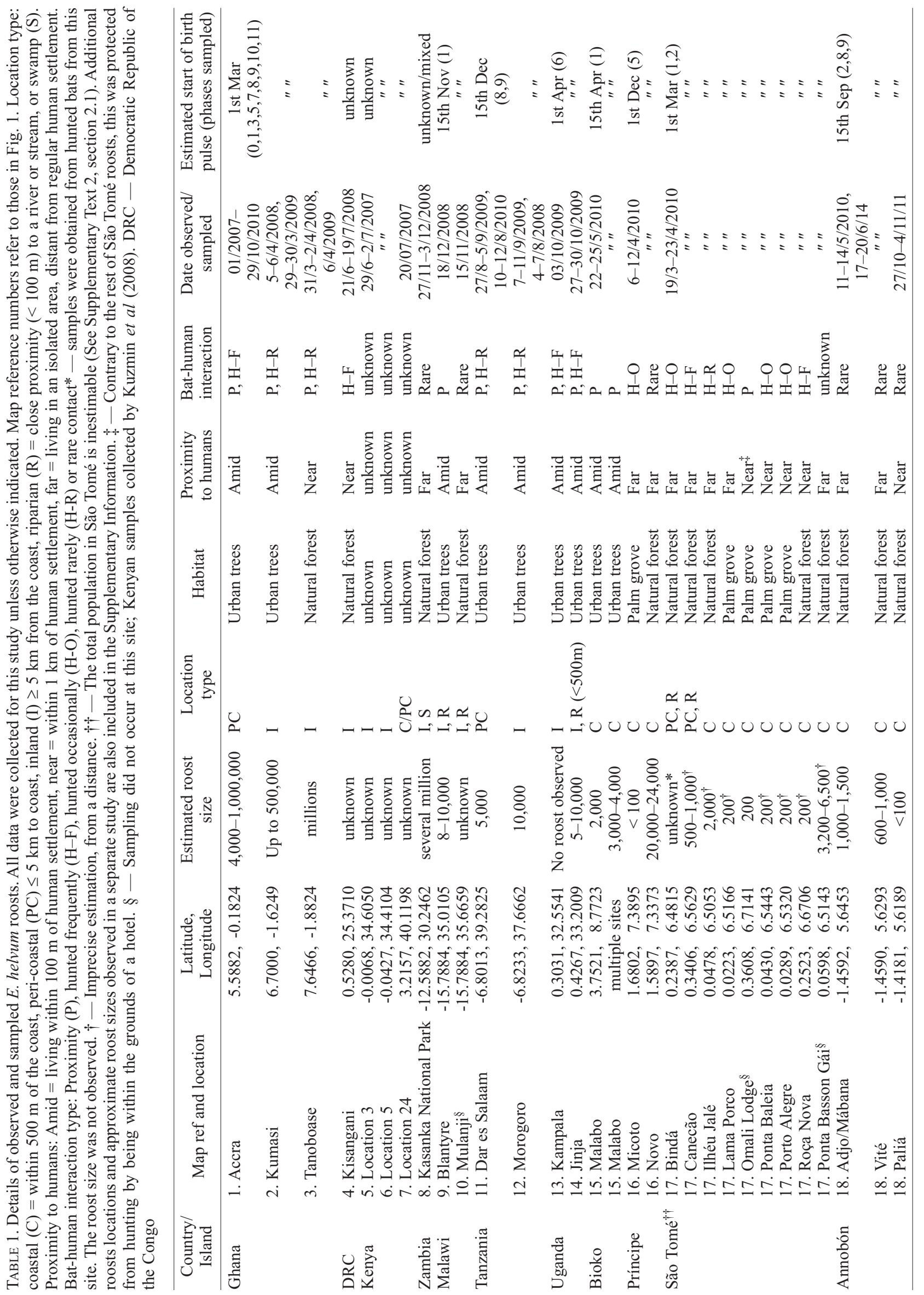


into one of the four age classes: neonate $(\mathrm{N} ;<2$ months), juvenile (J; $2-<6$ months), sexually immature (SI; $6-<24$ months) or adult ( $\mathrm{A} ; \geq 24$ months). Based on the timing of sampling in relation to the birthing season, a subset of SI individuals were further classified into 6-month age groups SI.1, SI.2 and SI.3 (6 - <12, $12-<18,18-<24$ months, respectively). Additionally, for a small proportion of bats that were hunted or euthanased following capture, age in years was assessed from upper canine tooth cementum analysis, as described in (Peel et al., 2016).

\section{Demographic and Morphometric Analyses}

The data were explored to assess the age and sex composition of roosts, and whether significant variation existed across sampling sites, using univariate comparisons and $\chi^{2}$ tests (performed in R - R Core Team, 2014). In some locations, agespecific data were biased as age determination by tooth cementum analyses was undertaken on only a subset of the individuals captured. The specific age composition of each roost was therefore standardized at each roost site according to the proportion of all individuals caught within each age class. Differences between mean forearm length and body mass between sexes and across locations were assessed using Student's $t$-tests and ANOVAs, respectively (R Core Team, 2014).

\section{Estimation of Roost Size}

Estimation of E. helvum roost size was challenging and no single method was suitable in all locations. Here, two methods previously used for this species were employed, depending on site suitability. Attached neonates are difficult to observe reliably and were not counted using either method. Firstly, roost counts were conducted during the day, when the bats had settled after returning to the roost at dawn, using a similar method to that described previously (Baranga and Kiregyera, 1982). Initially, the numbers of bats per roosting cluster were counted in a small number of easily observable clusters (usually 5-30 bats). Working sequentially along each branch in each tree, counts were then extrapolated for all clusters in the tree, and subsequently for each tree in the roost. This method was used in Malawi, Tanzania, Uganda and Bioko during the sampling periods shown in Table 1. The method was also used from 2008-2012 in Accra, Ghana (Hayman et al., 2012; Fahr et al., 2015), and from 2002-2008 in Uganda (Perpetra and Kityo, 2009).

Secondly, emergence counts were conducted at the largest identified roosts in Príncipe and São Tomé. In Príncipe, the roost studied and the technique used were the same as those described by Dallimer et al. (2006). From a vantage point $600 \mathrm{~m}$ $\mathrm{N}$ of the roost $(1.59552 \mathrm{~N}, 7.33677 \mathrm{E})$, the number of bats emerging per minute was counted by one observer over two consecutive nights using a stopwatch and tally counter. Initially it was possible to count individual bats, however as the rate of emergence increased, bats were counted in tens or fifties. Counting ceased when light conditions deteriorated. The same method was used at Ponta Basson Gái in São Tomé, by two observers on each of two consecutive nights from a vantage point ca. $800 \mathrm{~m}$ $\mathrm{S}$ of the roost $(0.05218 \mathrm{~N}, 6.51404 \mathrm{E})$.

Following Dallimer et al., (2006), roost emergence counts (in cumulative count $/ \mathrm{min}$ ) were fitted to a logistic growth curve so that the emergence count could be extrapolated into the period after which darkness prevented continuation of counting, and an estimate of the total roost size obtained, and rounded to the nearest 100 . The formula used was:

$$
y=\frac{k}{1+e^{a(t-x)}}
$$

where $y=$ cumulative count $/ \mathrm{min}$,

$k=$ the predicted maximum number of bats emerging,

$t=$ the time taken to the inflection point of the logistic curve (corresponding to the peak of a plot of count $/ \mathrm{min}$ ),

$a=$ the growth rate parameter,

$x=$ the time in minutes since the count started.

At Annobón, the steep terrain and dense forest precluded systematic roost or nightly emergence counts, and roost sizes were only roughly estimated. The roost in Kasanka National Park, Zambia has been estimated as the largest $E$. helvum roost known. Bats in this roost emerge over $360^{\circ}$ and roost over a swamp containing crocodiles, making it almost impossible to obtain an estimate of the roost size beyond that of 'several million'. Sufficient manpower was not available to attempt a systematic count for this location.

\section{Bat-Human Interactions}

In each country, local inhabitants were questioned informally regarding the location and seasonality of known E. helvum roosts, threats to the bats such as hunting for human consumption, removal of roost trees or other persecution, and whether these factors had changed over living memory. Additionally, in the Gulf of Guinea islands, local residents were interviewed using the same questionnaire-based surveys as previously used in Ghana (Kamins et al., 2011). These surveys included questions on hunting, butchering and cooking methods, the structure of the commodity chain, offtake levels and perceptions of the risk of exposure to zoonotic diseases.

\section{Roost Descriptions}

Roost descriptions were produced, including photographs, anecdotal observations and a summary of the demographic composition, morphology, size, seasonality, and bat-human interactions [Supplementary Text 2, Supplementary Fig. S1, Supplementary Table S1 and the iNaturalist website (http://www. inaturalist.org/taxa/40827-Eidolon-helvum)]. The iNaturalist community science project includes the ongoing addition of unpublished E. helvum data.

\section{RESULTS}

\section{Study Roost Characteristics}

Phase shifts in the timing of reproduction were observed across sampling locations (Fig. 2), and the 'phase' of sampling was therefore defined in analyses as the estimated time since the beginning of the birth pulse (Table 1). Roost size estimates based on direct counts of clusters of bats at roost sites varied from less than 100 to several million (Table 1). Predicted roost sizes extrapolated from emergence counts fitted to logistic growth curves were 21,800 (95\% CI 19,700-24,400) in Novo (Príncipe) and ranged from $3,400(3,200-3,700)$ to $5,300(5,200-5,400)$ in Ponta 


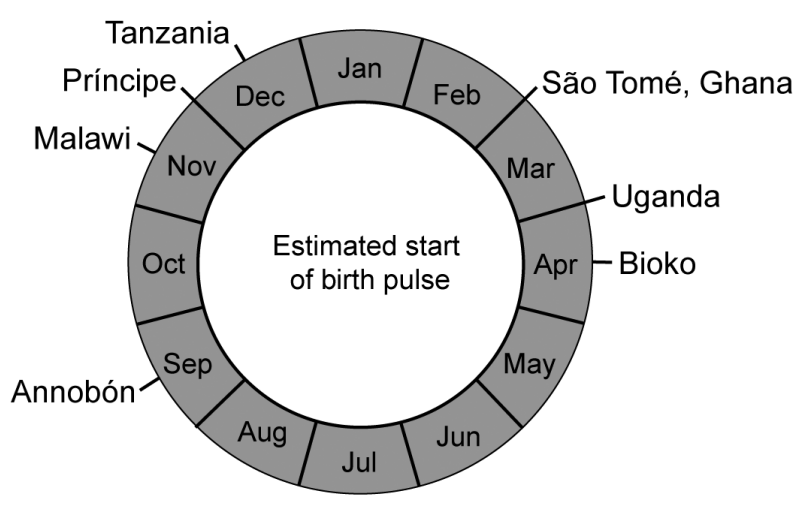

FIG. 2. Timing of estimated start of birth pulse across E. helvum roosts studied

Basson Gái (São Tomé), with total counts and precision varying considerably among observers (Fig. 3 and Supplementary Table S1). The cumulative counts from the 11th April, 2010 in Novo were still increasing exponentially at the end of the counting period, and a logistic curve could not be fitted.

\section{Demography and Morphology}

Sex composition of the roosts varied significantly across sampling locations (all individuals: $\chi^{2}=117.9$, d.f. $=10, P<0.001$, adults only: $\chi^{2}=169.7$, d.f. $=10, P<0.001$ - Fig. 4A), however data were insufficient to statistically assess whether this was as a function of reproductive phase (months since the beginning of birth pulse). Marked difference in sex-composition existed between roosts at Dar es Salaam and Morogoro, cities separated by ca. $180 \mathrm{~km}$, and sampled within two to three weeks on two consecutive years. Similarly, inverse sex compositions were observed in DRC and Kenya, where samples were collected from both locations in late-June to mid-July, though this was not in the same year. Field observations also suggest some age and sex segregation among roosts, at least at certain times of the year. For example, in São Tomé, most bat hunters we followed targeted small day-roosts in coconut palms where whole clusters of 4-10 bats were generally killed with one shot.
A

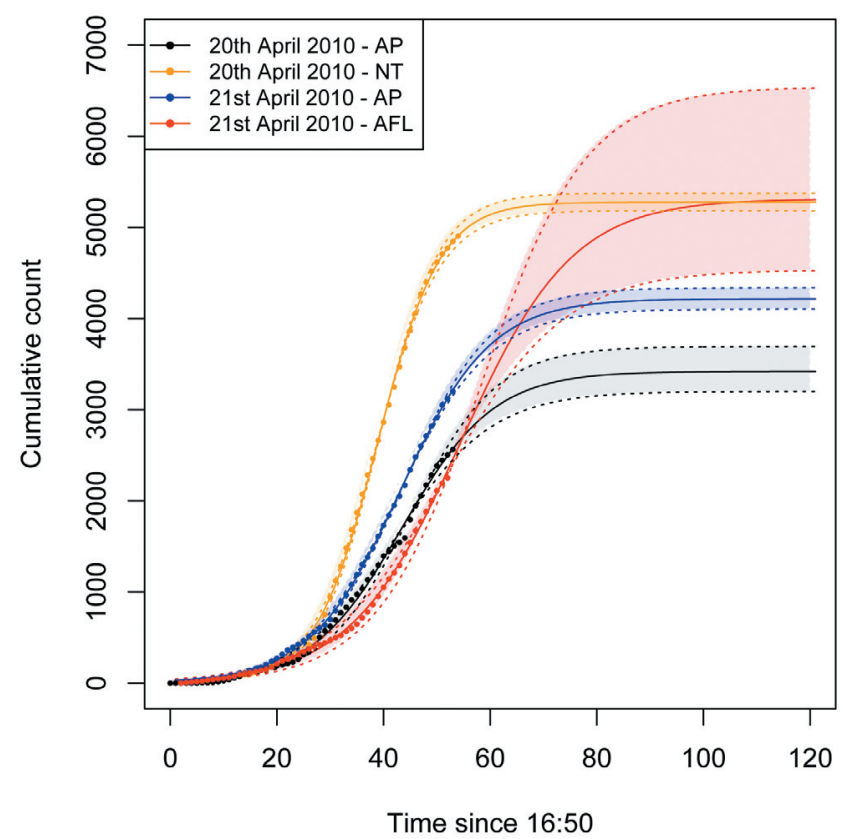

B Novo colony, Príncipe

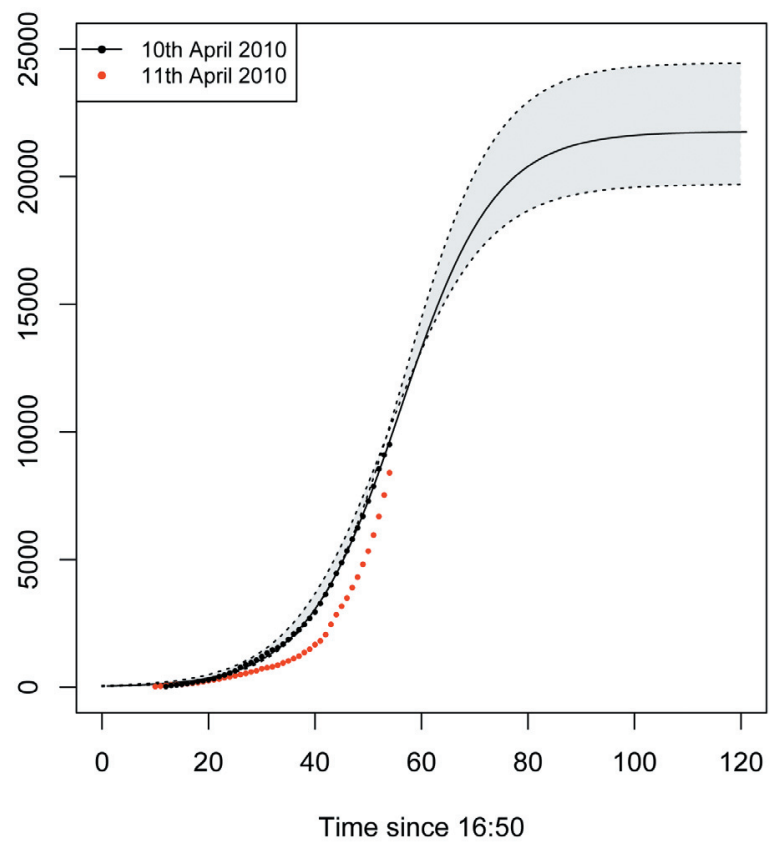

FIG. 3. Cumulative number of bats counted emerging from E. helvum roosts at dusk. Points indicate observed cumulative counts (from time of first bat observed to darkness), the solid line gives the predicted cumulative count from the logistic growth model, and dotted lines and shading give 95\% confidence intervals for those estimates. See Supplementary Table S1. Dates of observations and initials of the observers are given in each plot. A - In São Tomé, counts were performed by two observers on each of two nights (with three different observers in total); B - In Príncipe, counts were performed by one observer (AP) on two consecutive nights. It was not possible to fit a logistic curve to the counts on the second night. AP = Alison Peel, AFL = Andrés Fernandez Loras, NT = Aristides Santana (Nity). Predicted roost sizes were: Novo 10/4/10 AP 21,749 (19,689-24,441); Ponta Basson Gái, São Tomé: 20/4/10 AP 3,420 (3,200-3,693), 20/4/10 NT 5275 (5,183-5,374), 21/4/10 AP 4,216 (4,103-4,338), 21/4/10 AFL 
A

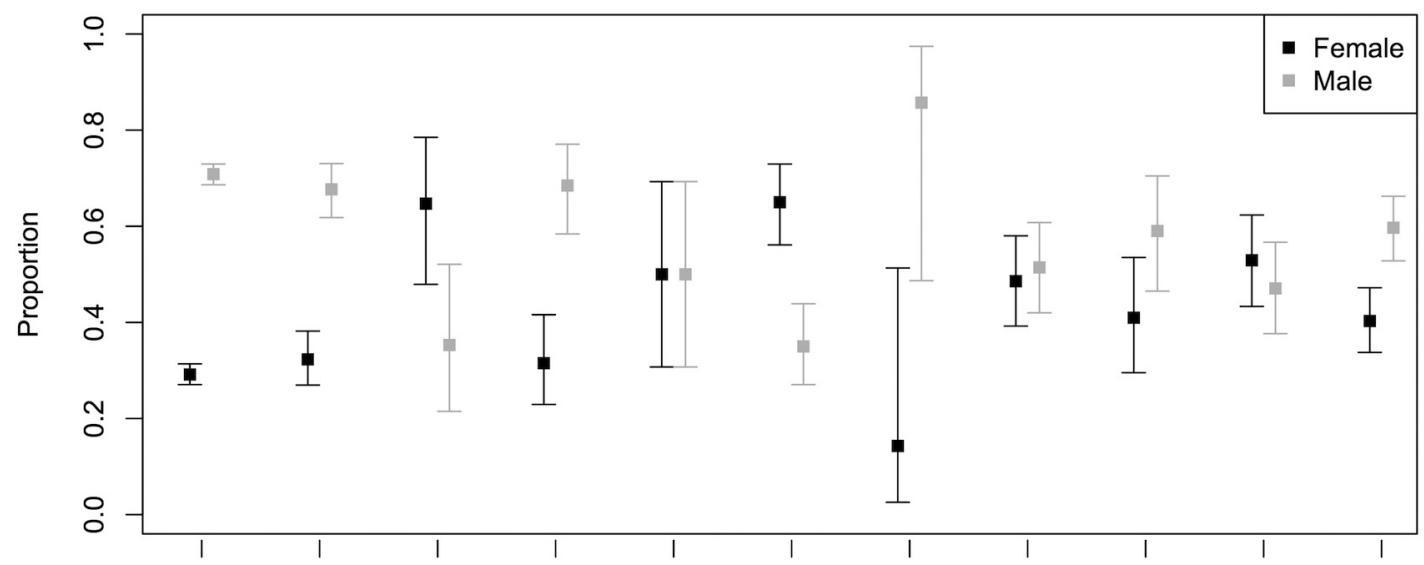

B

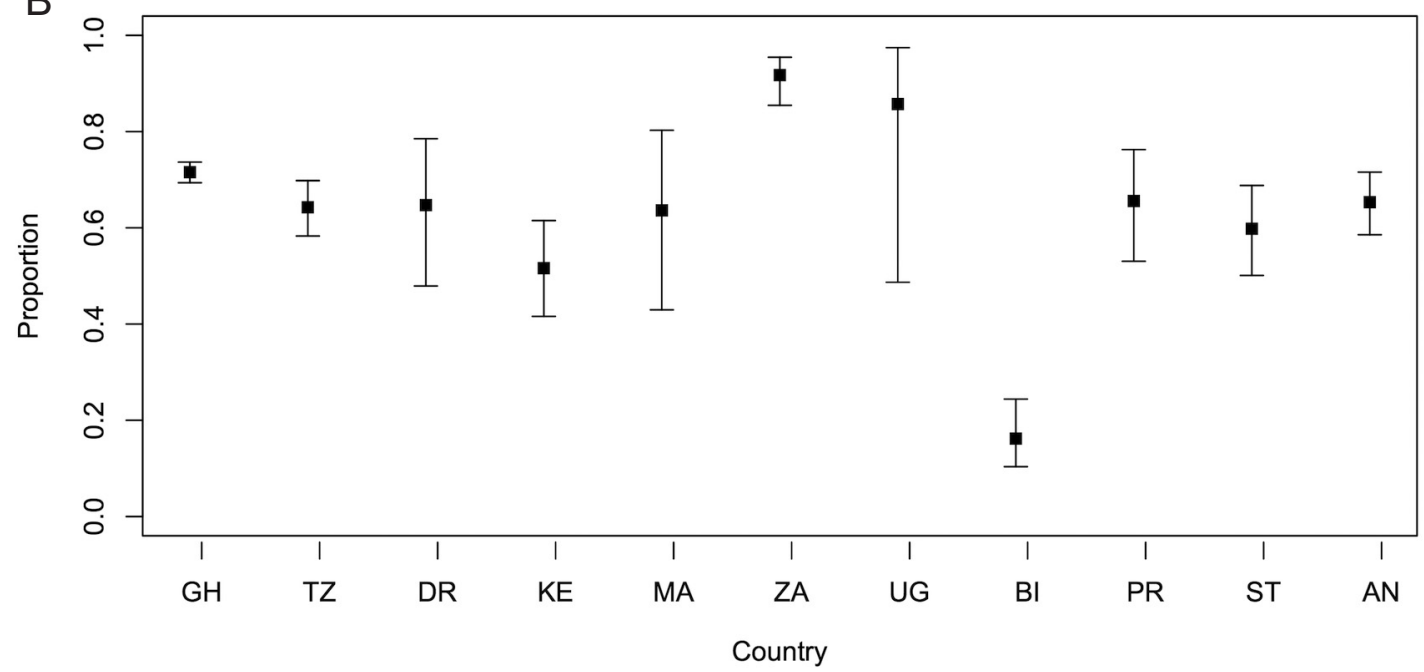

FIG. 4. Demographic composition of E. helvum bats across all sampling locations. A - Sex composition, indicating proportion of males and females and 95\% confidence intervals; B - Age composition, indicating proportion of adults and $95 \%$ confidence intervals. Countries: GH (Ghana), TZ (Tanzania), DR (DRC), KE (Kenya), MA (Malawi), ZA (Zambia), UG (Uganda), BI (Bioko), PR (Príncipe), ST (São Tomé), AN (Annobón)

Some coconut groves (e.g., Bindá) contained wholly or mostly adult males, and others (e.g., Ponta Baleia) consisted primarily of lactating females, juveniles and second-year sexually immature bats. In the latter sites, further substructure was observed: some clusters comprised wholly lactating females and juveniles, and others comprised wholly sexually immature bats.

Analyses of teeth from juvenile and SI bats suggested that the first annulus is laid down at approximately 13-14 months of age. The oldest bat, a 15-year old (range 14-16) adult male from Dar es Salaam, Tanzania, represents the oldest record for wild E. helvum. The age range of reproductively active females (pregnant or lactating) determined from teeth analyses was 2-14 years.
The overall age composition of 1,010 individuals from countries other than Ghana (A 61.4\%, SI $26.2 \%, \mathrm{~J} 1.0 \%, \mathrm{~N} 11.4 \%$ ) was comparable to previously published Ghanaian data (A 72.1\%, SI $19.8 \%$, J 7.9\%, N $0.2 \%, n=1305$ bats - Hayman et al., 2012). Highly significant differences in the proportion of adults and non-adults among roosts $\left(\chi^{2}=826.8\right.$, d.f. $=27, P<0.001-$ Fig. 4B $)$ are likely attributable to the reproductive phase and roost type. For example, very few neonates were ever observed in Ghana despite near-term pregnancies and none were seen in Tanzania, whereas attached, suckling neonates were caught with their mothers during sampling in São Tomé and Malawi. However, insufficient data were available to test these associations statistically. Adult age composition based on tooth cementum analyses (Fig. 5) 


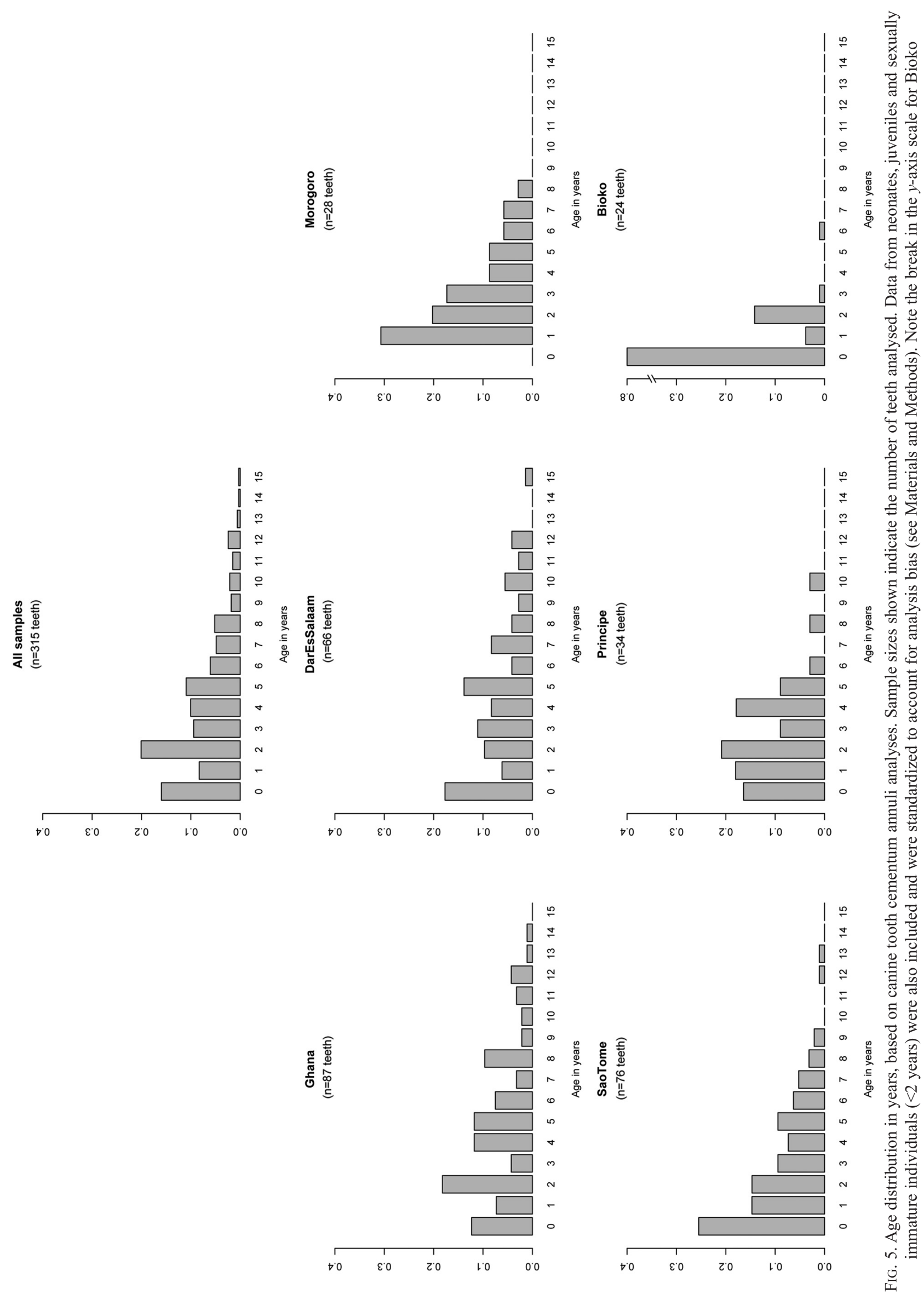


suggested regional differences. For example, Dar es Salaam (Tanzania, mean 6.4 yrs, $\max 15$ yrs, $n=53$ adults) and Accra (Ghana, mean 6.0 yrs, max 14 yrs, $n=76$ adults) had 'older' and more evenly spread age distributions than Bioko (Equatorial Guinea, mean 2.4 yrs, max 6 yrs, $n=16$ adults), Príncipe (mean $4.2 \mathrm{yrs}, \max =10 \mathrm{yrs}, n=23$ adults), Morogoro (Tanzania, mean $4.5 \mathrm{yrs}$, $\max 8 \mathrm{yrs}, n=24$ adults) and São Tomé (mean 4.8 yrs, $\max =13$ yrs, $n=57$ adults).

Body mass and forearm length data were available from 2,329 and 2,280 individuals, respectively (Table 2 and Fig. 6). Adult forearm length and body mass at Annobón were significantly smaller $(t=-32.7$, d.f. $=183, P<0.001$ and $t=-26.5$, d.f. $=182, P<0.001$, respectively) than $E$. helvum in continental Africa or other Gulf of Guinea islands despite unremarkable age and sex compositions (Supplementary Fig. S1). Annobón data were omitted from further analyses. Adult females were significantly larger than adult males in forearm lengths and body mass $(t=5.5, d . f .=665, P<0.001$ and $t=2.3$, d.f. $=683, P<0.05$, respectively), although the differences were small (mean forearm 122.8 versus $121.4 \mathrm{~mm}$ and mean body mass 273.9 vs. $269.4 \mathrm{~g}$, for females and males, respectively). Age was positively correlated with forearm length and body mass (Fig. 6 and Table 3).

\section{Bat-Human Interactions}

The proximity of E. helvum roosts to human populations, the public perceptions of the species, and the degree to which it is persecuted or hunted vary strongly across its geographical range (Supplementary Fig. S1 and Table 1). At one extreme, $E$. helvum bats roost in the middle of busy cities and urban areas (Dar es Salaam, Morogoro, Accra, Malabo, Kigali, Bata, Libreville, Kisangani and previously in Kampala). In these locations, while the bats may be resented for their early morning noise, excrement under roost sites, and damage to roost trees, they are generally tolerated and ignored. Hunting in these, and other, areas is either virtually absent as a result of dietary preferences (Tanzania, Malawi, Zambia) or superstition (Bioko, Annobón), or is limited to relatively small-scale offtake with slingshots (Accra, Jinja) or mist nets (Kisangani) due to restrictions on using guns in cities. While hunting is reduced in cities, other forms of persecution such as removal of roosting trees (Accra and Kampala) or 'smoking out' roosts (Kampala) still have the capability to deter roost

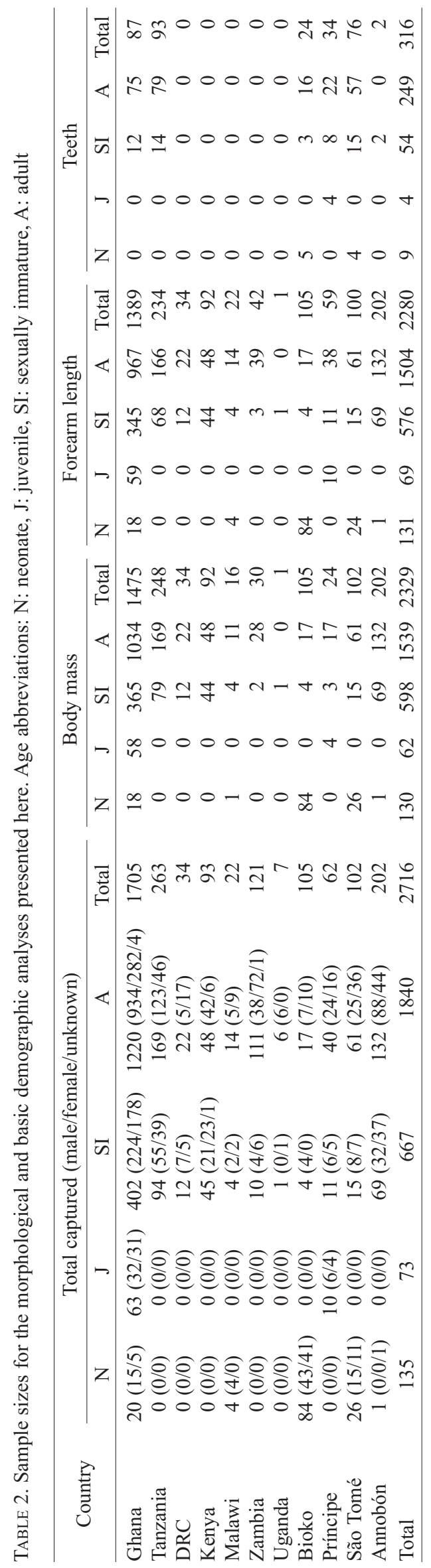


A

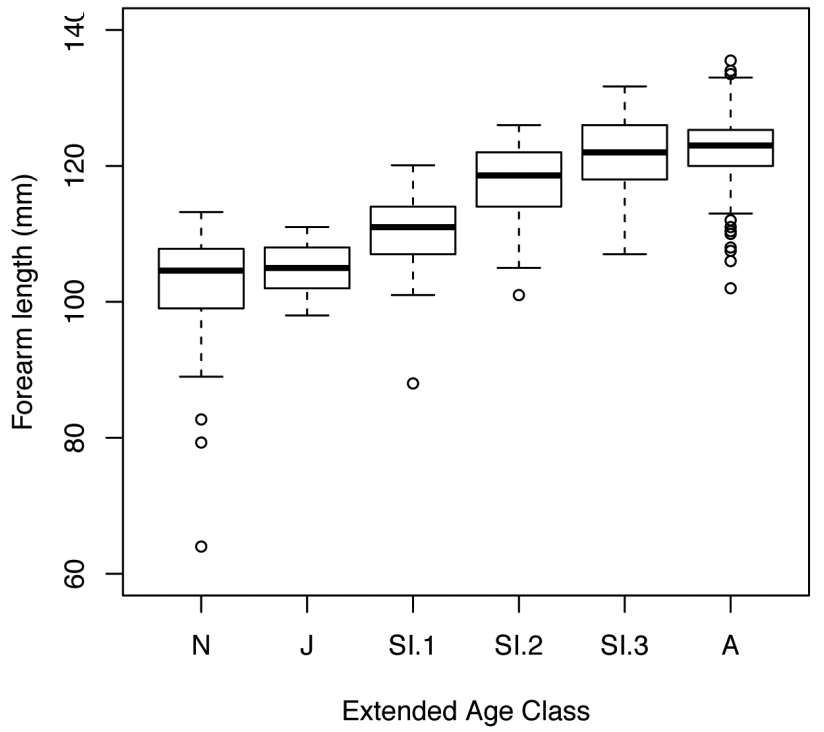

B

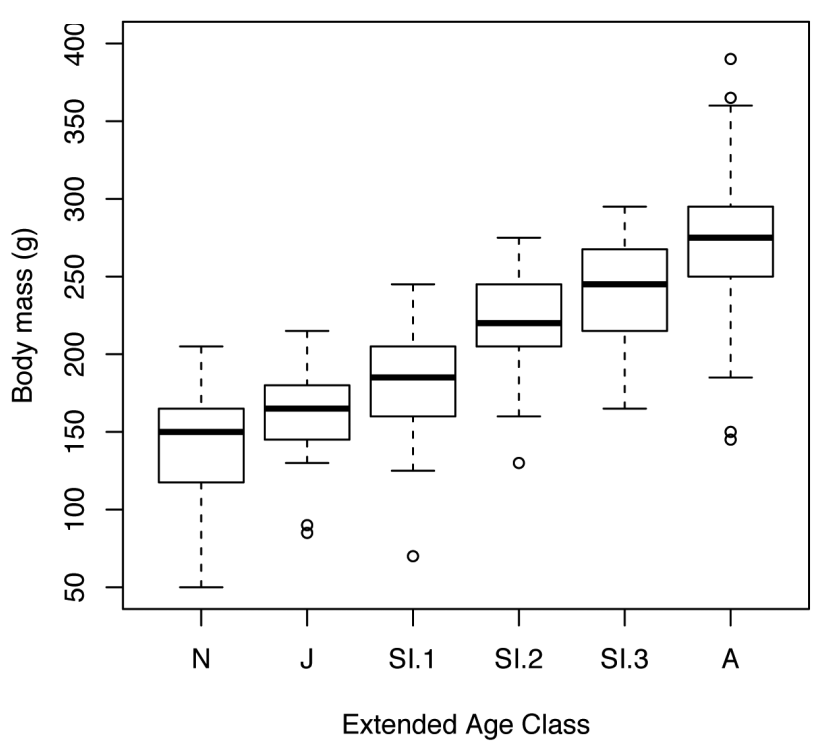

Male

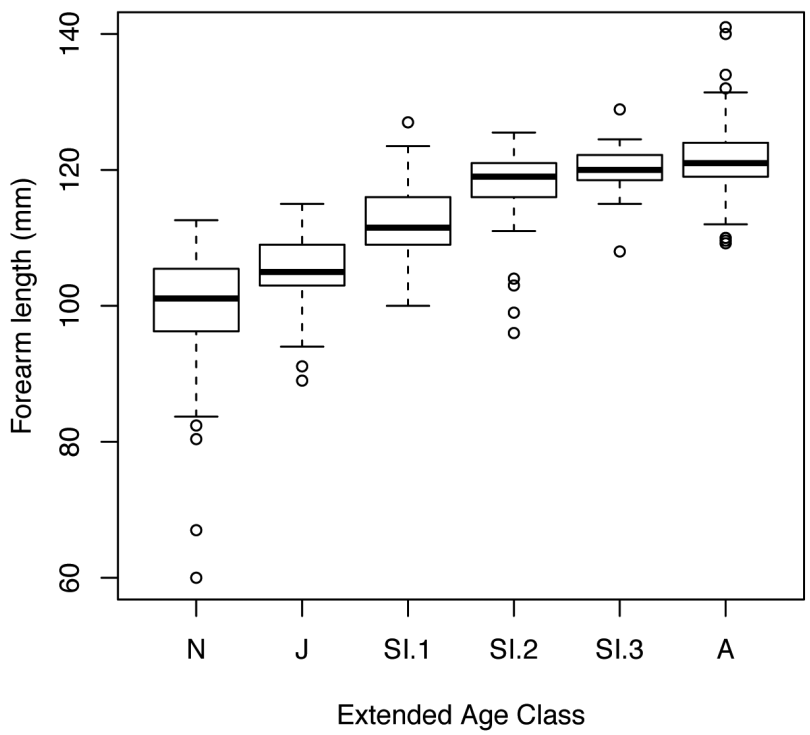

Male

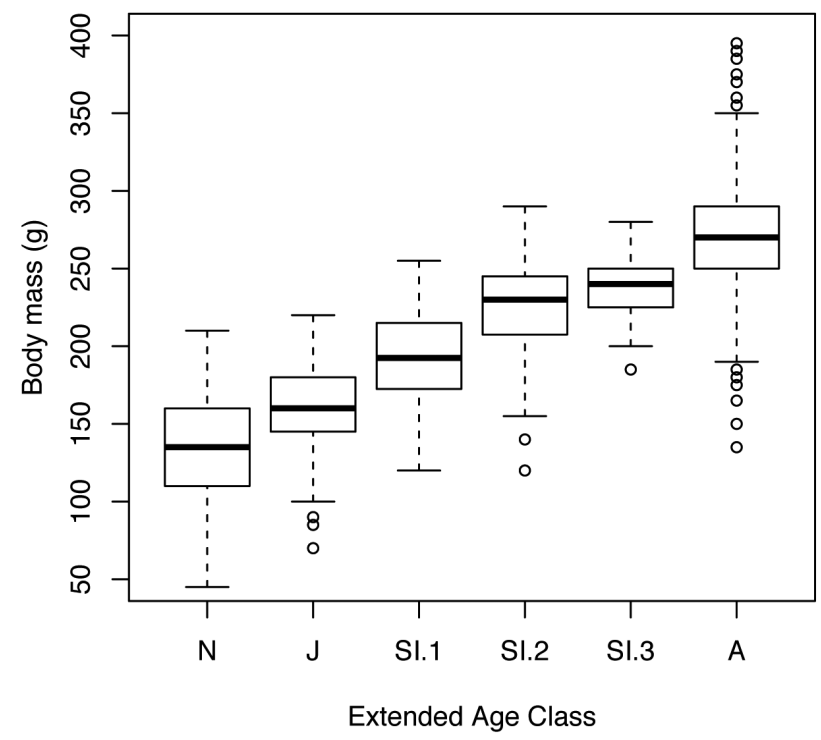

FIG. 6. Plots of E. helvum (A) forearm length and (B) body mass by sex and extended age class (including neonates, juveniles (J), first year (SI.1) and second year (SI.2 and SI.3) sexually immatures, and adults (A)). All roosts except for Annobón were included (following results from country analyses). Box and whisker plots: median (black line), 25th and 75th percentile (box) and $1.5 \times$ the interquartile range (dotted line) values. Outliers are shown as individual points

formation and severely reduce local population size.

On the other extreme, most notably on the island of São Tomé, hunting pressure is high (Carvalho et al., 2015a, 2015b) and large E. helvum roosts are found only in remote areas, further away from human settlements. Bat roosts in the north of São Tomé were observed to be highly mobile, and regularly vacated roost sites in response to hunting in the area. The only exception in the north of São Tomé was a small roost of bats within the grounds of a luxury lodge in the city of São Tomé, where bats were protected from hunting. Protection was also clearly provided by roosting in inaccessible locations in the south and central west of the island, where guns and ammunition are not readily available. While hunted roosts are often remote, remote roosts do not exclusively indicate hunting pressure (e.g., the large roost in Kasanka NP, Zambia and likely countless unknown roosts across the continent). 


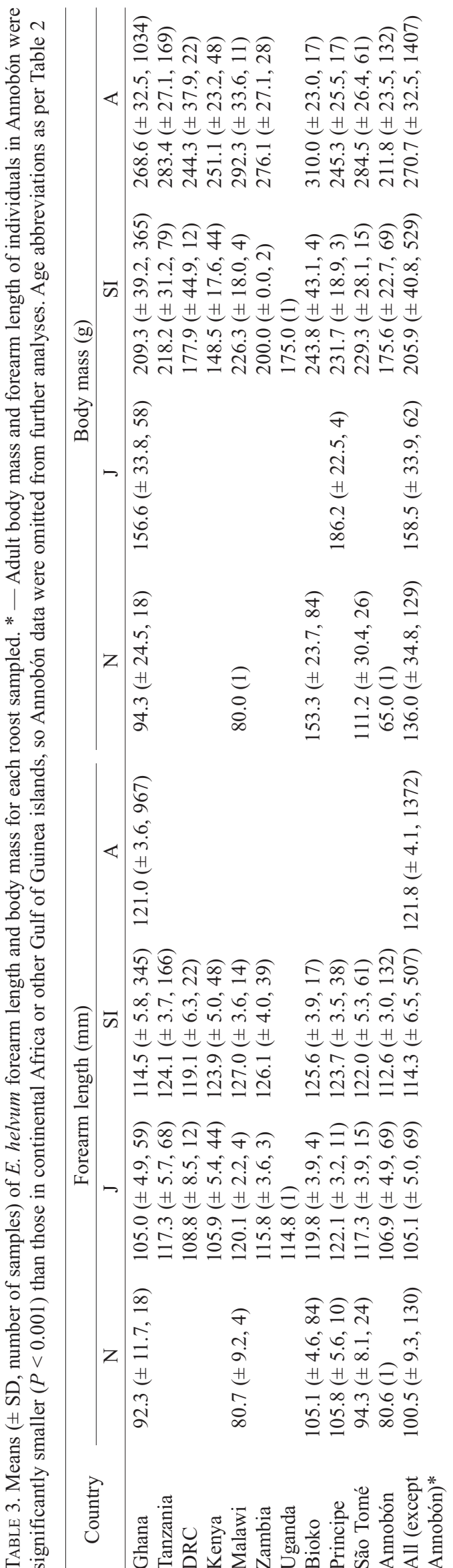

\section{DISCUSSION}

Although E. helvum is one of the most common bat species in Africa, existing data on the seasonal variation of roost location, size and composition, and bat-human interactions are fragmented and incomplete. The data presented here have limitations; however they are the most comprehensive for this species and address some aspects of this paucity of ecological data. The significantly smaller adult body size of E. helvum in Annobón compared with continental Africa or other Gulf of Guinea islands is consistent with previous morphological and genetic studies of E. helvum on Annobón (Juste et al., 2000; Peel et al., 2013) and with some studies on the evolution of mammalian body size on islands (Angerbjörn, 1985; Burness et al., 2001).

\section{Seasonal Variation in Roost Location, Size and Composition}

Typical of many wildlife species, seasonality is central to the ecology of E. helvum. Across continental and island roost sites spanning from Malawi to Ghana, we found considerable diversity in the age and sex composition of roosts, roost sizes, seasonality of reproduction and migration, and also the degree to which the migration occurs (see Supplementary Text 2). Fission-fusion social structures are increasingly being recognised in bats (e.g., Storz et al., 2001; Willis and Brigham, 2004; Kerth et al., 2011). Not previously formally described for E. helvum, we contend that a fission-fusion social structure seems likely and manifests as observations of different roost 'types' across space and time, related to seasonal reproduction and biased dispersal tendencies. For example, the strong male bias documented in the Dar es Salaam roost here is consistent with findings in Accra, Ghana, where telemetry studies demonstrated different migration patterns for the two sexes (Hayman et al., 2012). This may give an indication that pregnant females migrate regionally to utilise seasonal changes in fruit and nectar, and although long-range migration over thousands of kilometres has also been demonstrated for male E. helvum (Richter and Cumming, 2008), some E. helvum males may prioritise remaining 'resident' in the roost to protect territories (e.g., as with Pteropus poliocephalus (McCracken and Wilkinson, 2000)) over optimal nutrition. Similarly, we observed a male bias in Kenya during the period when females from that region would have been expected to be giving birth (Mutere, 1980), and at 
the same time of the year that we observed a female bias in the DRC (though in different years). The male bias in Kenya corresponds with previous findings in this area, and observations of E. helvum migrations into the north-west of the DRC from a north-easterly direction in May and June (Lang and Chapin, 1917b). While these data are sparse, the potential for connectivity between these regions is not unreasonable, given the known migratory range of this species (Richter and Cumming, 2008). Although long-range migration over thousands of kilometres has been demonstrated for male E. helvum (Richter and Cumming, 2008), clearly, the social and sexual behaviour of E. helvum is an area requiring further study.

Observed differences in age class (N, J, SI, A) composition among sampling sites are also expected to reflect seasonal reproductive timing, with the potential for added sampling biases. For example, while it is likely an extreme case, results from Bioko illustrate the potential for an age sampling bias. Here, 84/105 (80\%) of bats captured were less than two months old: a result of the inadvertent selection of a sampling site next to a 'nursery roost', at the time of the year when juveniles were being weaned, and by catching in the night when mothers appear to leave their offspring at the roost while they feed. Although this behaviour has not been reported for E. helvum it is common in Pteropus spp. (Eby, 1995), for example. Further spatial age-structuring within apparent nursery roosts (clumping of SI vs. lactating females and their pups) was identified in São Tomé, and is consistent with reports from Uganda (Kingdon, 1974).

In addition to differences in proportions of each age class, age distributions within the adult age class varied among roosts (Fig. 5). For example, Dar es Salaam showed an 'older' adult age distribution compared to the relatively 'young' adult distribution for Morogoro; both roosts are in Tanzania ca. $180 \mathrm{~km}$ apart and reproductively synchronized. These data came from a single time point, and while differences in age composition may be partially a result of differences in sample size (Dar es Salaam $n=66$, Morogoro $n=28$ ), the Morogoro roost was anecdotally reported as being present in the area only 'recently'. Morogoro also lacked the male bias present in Dar es Salaam, and could therefore be another indication of the presence of unobserved roost types related to differences in timing and degree of roost migration (Hayman and Peel, 2016). Studies in other fruit bats have identified heterogeneity in age composition among roosts. For example, there are indications that some harems in Cynopterus sphinx are founded by nulliparous females of the same age cohort (Storz et al., 2000).

Resultant seasonal fluctuations in roost size associated with a fission-fusion social structure can be extreme, for example, a 50-70 fold difference between maximum and minimum roost size of the Accra roost in Ghana (Fahr et al., 2015) and a rapid seasonal increase from zero to several million individuals at Kasanka National Park in Zambia (Richter and Cumming, 2006). Lower proportions of SI individuals were captured in the roost at Kasanka National Park in Zambia, perhaps indicating younger animals are less likely to make longdistance migrations. In this study and others (Richter and Cumming, 2006), the Kasanka roost contained females in both very early pregnancy and lactation, suggesting individuals had migrated from regions with asynchronous birthing seasons. Although the seasonal biology of this species and differences in reproductive seasons in roosts situated north and south of the equator have been frequently noted (Eisentraut, 1941; Anciaux de Faveaux, 1978; Funmilayo, 1979; Richter and Cumming, 2006), some authors still refer to a single time of breeding. Across the roosts sampled here, plasticity in the timing of the birth pulse was observed: starting in March, April, September, November or December (see Fig. 2). Presumably, this relates to the timing of wet and dry seasons (driven by the Intertropical Convergence Zone (Suzuki, 2010)), however it is unclear why São Tomé and Príncipe have asynchronous birth pulses when their climates are so similar (Deutscher Wetterdienst, 2016).

\section{Estimation of Roost Sizes}

Obtaining reliable size estimates of bat roosts is crucial for undertaking hunting and population sustainability calculations but is notoriously difficult (O'Shea et al., 2003). Even when using standardized, well-described protocols, insurmountable difficulties may be encountered for some roosts. For example, the daytime roost count method used to count $E$. helvum in easily accessible, broad-canopy trees in Ghana (Hayman et al., 2012) and Uganda (Baranga and Kiregyera, 1982; Perpetra and Kityo, 2009) was not suitable for dense-leafed Indian mast trees in Dar es Salaam, Palm trees in Jinja and São Tomé, or densely forested areas in Annobón and Tano Sacred Grove, Ghana. Likewise, the emergence count method (Dallimer et al., 2006) cannot account for multiple flight paths from one observation point 
and, here, in Príncipe and São Tomé, was compromised by densely forested and rugged terrain. Particularly in São Tomé, the roost and emergence flight path was partly obscured from the observation point, therefore the counts presented here are expected to be only a fraction of the total population size. The Novo roost in Príncipe was larger $(19,700$ $-24,400)$ than during a previous estimate $(10,500$ 14,000 - Dallimer et al., 2006), however it is not possible to draw conclusions on population trends since the latter study was undertaken in January when females were lactating and bats are dispersed more widely across the island (Supplementary Text 2, section 2.6). Furthermore, it should be noted that fitting simple mathematical models to field data requires a number of untested assumptions. Firstly, the model assumes that the number of bats emerging per minute follows a normal distribution over the period of emergence (including after dark - Betke et al., 2008; Hristov et al., 2010), yet this has not been explored for fruit bats. Secondly, given that predicted times to peak emergence (i.e., the inflection point of the logistic curve, $t=39-56$ minutes after the first bats were observed emerging) are similar to the times at which observations were ceased (46-53 minutes), the model is highly sensitive to the accuracy of the counts at this point. Unfortunately, this is also when the counts are expected to be the least accurate, due to poor visibility, observer fatigue, and large numbers of bats emerging. The relationship between true fruit bat emergence counts (assessed using videos) and observer emergence counts is non-linear, and observer precision has been found to decrease as the rate of emergence increases (Westcott and McKeown, 2004; Forsyth et al., 2006). These factors may be a reason for the inability to fit the counts from the 11th of April, 2010 in Novo to a logistic curve. Alternative sigmoidal functions could have been equally appropriate to fit to the data, and may have given different estimates (Forsyth et al., 2006).

Valuable longitudinal studies estimating $E$. helvum roost size have been performed in Accra, Ghana (Hayman et al., 2012; Fahr et al., 2015) and Kampala, Uganda (Perpetra and Kityo, 2009), with shortterm abrupt declines and steady population declines over several decades reported, respectively (Mickleburgh et al., 2009; Perpetra and Kityo, 2009). With the exception of Príncipe, population size estimates conducted for this study were single point-estimates in roosts where no previous roost counts had been reported. Ongoing use of standardized protocols over time and space will ultimately enable long-term regional and distribution-wide population estimates to be obtained and collated (O'Shea et al., 2003). This is particularly important in determining whether reported population declines in some parts of the species' distribution are local trends or representative of overall population declines. While many of the large aggregations of E. helvum included in the current study are well known, few are well studied, and investigations here identified a number of roosts in central and southern Africa not previously reported (Supplementary Text 2). It is unclear, therefore, what proportion of the total $E$. helvum population is accounted for in existing studies.

\section{Bat-Human Interactions}

Various hunting methods reported here (shooting, slingshotting, capture in nets, and hitting individuals that have fallen to the ground) were consistent with those already documented for E. helvum (Mickleburgh et al., 2009). An additional method was identified in São Tomé, that is, using wire mesh traps with a fruit lure and a one-way entrance funnel ('kapuélé' — Supplementary Text 2, section 2.5).

The proximity of E. helvum roosts to human populations and the degree of bat-human interaction appeared to be linked in the roosts we studied. In locations where E. helvum is regularly hunted (e.g., São Tomé, Carvalho et al., 2015 and Ghana, Kamins et al., 2011), bats are naturally discouraged from roosting near to human settlements and retreat to more remote and protected areas (e.g., Tano Sacred Grove, and the large roosts in São Tomé and Príncipe). Urban roosts in bat-hunting regions tend to be in the tallest trees available, and often within sites that provide some form of 'sanctuary' where hunting is discouraged. This includes hospital grounds (Accra, Kampala), embassies (Accra, Libreville), botanical gardens (Accra, Ile-Ife (Fayenuwo and Halstead, 1974)), hotels (São Tomé), palace gardens (Kano (Barau et al., 2013)), zoos (Kumasi) and military, private or corporate compounds (Accra, Yaounde). Alternatively, it may be that these locations are some of the few areas within these cities with sufficient numbers of large, tall trees remaining to accommodate large roosts, since roosts in regions where E. helvum were not hunted for bushmeat or regularly disturbed were also observed in hospital grounds (Muheza, Nguludi), embassies (Malabo), and private compounds (Dar es Salaam). Where hunting was absent or essentially restricted, however, easily accessible large roosts also existed in 
trees lining the streets of busy urban areas (Malabo, Accra, Blantyre, Dar es Salaam, Morogoro).

These different scenarios of human-bat interaction may have implications for the relative risk of spillover of zoonotic pathogens from bats to humans. While city-dwellers living and working under roosts may be at greater risk from pathogens transmitted through aerosols containing bat urine or faeces, bat hunters and those who prepare bat carcasses may be at greater risk from pathogens transmitted directly through bites or via contact with body fluids such as blood.

While the roost in Kampala was noted as early as 1936 (Mutere, 1967), it is interesting that Lang and Chapin (1917a: 481) recorded for the Congo basin that fruit bats in the region "have nowhere well established roosts, nor are they present in numbers for a long period in any region except where cultivation of non-autochthonous fruit-trees helps provide an ample food-supply throughout the year, as in many eastern and western coastal districts." A transition from a nomadic lifestyle towards the existence of permanent roosts has been noted in Pteropus spp. in Australia (Plowright et al., 2011). However, the 'ample food supply' available to resident bats is nutritionally inferior to natural food sources (Eby et al., 1999; Markus and Hall, 2004) and is hypothesized to result in immunosuppression and a subsequent increased risk of Hendra virus transmission to horses (Plowright et al., 2015). Monitoring of the annual migrations of $E$. helvum roosts, or lack thereof, may therefore prove useful in the future for responding to any viral pathogens that might emerge in Africa. More generally, the implications of a fissionfusion structure on large-scale disease transmission of zoonotic diseases are worthy of further study.

This study makes a valuable contribution to sparse and patchy data on E. helvum ecology, demography and response to hunting published to date. However, here too, the intensity and frequency of sampling differed among the different roost sites and further targeted studies to address specific hypotheses on each component of the social structure, seasonal and spatial dynamics of this species are required. It is imperative that future studies of $E$. helvum take age and sex composition of sampled roosts into account in downstream analyses and consider the possible confounding effects of a fission-fusion social structure.

\section{ACKNOWLEDGEMENTS}

Thanks to Dr Tom O'Shea and three anonymous reviewers for thoughtful comments. The authors thank the governments of
Ghana, Tanzania, Malawi, Zambia, Uganda, Equatorial Guinea, and São Tomé and Príncipe for facilitating this research. For their invaluable support in planning and implementing the field work, we also thank the Wildlife Division of the Forestry Commission, and the Veterinary Services Directorate, Ghana; Zambian Wildlife Authority; Kasanka Trust; Malawi Ministry of Tourism, Wildlife and Culture, Malawi Ministry of Agriculture, Irrigation and Food Security; Tanzania Ministry of Livestock and Fisheries Development; Tanzanian Wildlife Research Institute; Sokoine University of Agriculture, Tanzania; Makerere University, Uganda; Equatorial Guinea Ministerio de Agricultura y Bosques; Equatorial Guinea Instituto del Desarrollo Forestal y Gestión de las Áreas Protegidas; Universidad Nacional de Guinea Ecuatorial; São Tomé and Príncipe Ministério de Agricultura, Desenvolvimento Rural e Pesca; Ecosystèmes Forestiers d'Afrique Centrale; Associação Monte Pico, São Tomé and Príncipe; Alex Torrance; Lucrecia Bilé Osa Ahara; Heidi Ruffler; Ricardo Castro César de Sá; Ricardo Faustino de Lima; Mariana Carvalho and Meyir Ziekah. The Supplementary Information benefitted from intellectual developments from the PREDICT project of the United States Agency for International Development (USAID) Emerging Pandemic Threats Program (Tanzania section), Ana Rainho, Jorge Palmeirim, Hugo Sampaio and the 'BirdLife International São Tomé Initiative' (São Tomé section). Funding for this study was provided by the Cambridge Infectious Diseases Consortium (grant VT0105 — AJP, DTSH, KSB), The Charles Slater Trust (AJP), Zebra Foundation for Veterinary Zoological Education (AJP), Isaac Newton Trust (AJP), the Wellcome Trust (DTSH, KSB), a David H. Smith postdoctoral fellowship (DTSH), the RAPIDD program of the Science and Technology Directorate, Department of Homeland Security, Fogarty International Center, National Institutes of Health (DTSH, JLNW), The Alborada Trust (JLNW), a European Union FP7 project ANTIGONE (Anticipating Global Onset of Novel Epidemics 278976) (ACB, JLNW, AAC) and a Royal Society Wolfson Research Merit Award (AAC).

\section{SUPPLEMENTARY INFORMATION}

Contents: Supplementary Text 1. Excerpts of observations and hypotheses of straw-coloured fruit bat (E. helvum) ecology put forward almost 100 years ago by Herbert Lang and James P. Chapin (sourced from Allen J. A., Lang H., Chapin J. (1917) The American Museum Congo expedition collection of bats); Supplementary Text 2. Roost descriptions, containing summaries of the characteristics of each E. helvum site sampled from or observed during this study, with additional information provided for those roost sites that have not been described in detail previously. Each summary includes a combination of observations and results from data analysis undertaken in this study, and anecdotal reports. GPS details for roost sites are given in Table 1 in the main article; Fig. S1. Plots of E. helvum adult forearm length and body mass by sex and sampling location; Table S1. Eidolon helvum emergence roost counts (observed number of bats emerging from roosts in São Tomé and Príncipe), and parameter estimates from the logistic growth model. Supplementary Information is available exclusively on BioOne.

\section{LiTERATURE Cited}

Anciaux de Faveaux, M. 1978. Définition de l'équateur biologique en fonction de la reproduction de chiroptéres 
d'Afrique central. Annals of the Royal Zoological Society of Belgium, 107: 79-89.

ANGERBJÖRN, A. 1985. The evolution of body size in mammals on islands: some comments. The American Naturalist, 125: 304-309.

Baranga, J., and B. Kiregyera. 1982. Estimation of the fruit bat population in the Kampala Bat Valley, Uganda. African Journal of Ecology, 20: 223-229.

BARAU, A. S., A. N. M. Ludin, and I. SAID. 2013. Socio-ecological systems and biodiversity conservation in African city: insights from Kano Emir's Palace gardens. Urban Ecosystems, 16: 783-800.

Bergmans, W. 1990. Taxonomy and biogeography of African fruit bats (Mammalia, Megachiroptera). 3. The genera Scotonycteris Matschie, 1894, Casinycteris Thomas, 1910, Pteropus Brisson, 1762, Eidolon Rafinesque, 1815. Beaufortia, 40: 111-177.

Betke, M., D. E. Hirsh, N. C. Makris, G. F. McCracken, M. Procopio, N. I. Hristov, S. TANG, A. Bagchi, J. D. REICHARD, J. W. HORN, et al. 2008. Thermal imaging reveals significantly smaller Brazilian free-tailed bat colonies than previously estimated. Journal of Mammalogy, 89: 18-24.

BurNess, G. P., J. Diamond, and T. FlanNery. 2001. Dinosaurs, dragons, and dwarfs: the evolution of maximal body size. Proceedings of the National Academy of Sciences of the USA, 98: 14518-14523.

Carvalho, M., F. Rego, J. M. Palmeirim, and J. E. Fa. $2015 a$. Wild meat consumption on São Tomé Island, West Africa: implications for conservation and local livelihoods. Ecology and Society, 20(3): 27.

Carvalho, M., J. M. Palmeirim, F. C. Rego, N. Sole, A. SANTANA, and J. E. FA. 2015b. What motivates hunters to target exotic or endemic species on the island of São Tomé, Gulf of Guinea? Oryx, 49: 278-286.

Dallimer, M., T. King, D. Cope, and M. Borge Jiana. 2006. Estimation of population density of Eidolon helvum on the island of Príncipe, Gulf of Guinea. Mammalia, 70: 48-51.

DeFrees, S. L., and D. E. Wilson. 1988. Eidolon helvum. Mammalian Species, 312: 1-5.

DeUTSCHER WeTtERDIENST. 2016. Klimadaten ausgewählter Wetterstationen: São Tomé und Principe. Retrieved February 6, 2016. http://www.dwd.de/DE/leistungen/klimadatenwelt/afrika/ps/saotome/land_020159_html_baustein_nas.html

EBY, P. 1995. The biology and management of flying foxes in NSW. Species Management Report, N.S.W. National Parks and Wildlife Service, Hurstville, 18: iii $+72 \mathrm{pp}$.

Eby, P., G. Richards, L. Collins, and K. Parry-Jones. 1999. The distribution, abundance and vulnerability to population reduction of a nomadic nectarivore, the grey-headed flyingfox Pteropus poliocephalus in New South Wales, during a period of resource concentration. Australian Zoologist, 31: 240-253.

EISENTRAuT, M. 1941. Beitrag zur Ökologie Kameruner Chiropteren. Mitteilungen aus dem Zoologischen Museum in Berlin, 25: 245-273.

Fahr, J., M. Abedi-Lartey, T. Esch, M. Machwitz, R. SuU-Ire, M. WiKelsKi, and D. K. N. DechmanN. 2015. Pronounced seasonal changes in the movement ecology of a highly gregarious central-place forager, the African straw-coloured fruit bat (Eidolon helvum). PLoS ONE, 10: e0138985.

FAYENUwO, J. O., and L. B. HalsteAd. 1974. Breeding cycle of straw-colored fruit bat, Eidolon helvum, at Ile-Ife, Nigeria. Journal of Mammalogy, 55: 453-454.
Forsyth, D. M., M. P. Scroggie, and E. McDonald-Madden. 2006. Accuracy and precision of grey-headed flying-fox (Pteropus poliocephalus) flyout counts. Wildlife Research, 33: 57-65.

FunMILAYO, O. 1979. Ecology of the straw-coloured fruit bat in Nigeria. Revue de Zoologie Africaine, 93: 589-600.

Hayman, D. T. S., and A. J. Peel. 2016. Can survival analyses detect hunting pressure in a highly connected species? Lessons from straw-coloured fruit bats. Biological Conservation, 200: 131-139.

Hayman, D. T. S., R. McCrea, O. Restif, R. Suu-Ire, A. R. Fooks, J. L. N. Wood, A. A. Cunningham, and J. M. RowCLIFFE. 2012. Demography of straw-colored fruit bats in Ghana. Journal of Mammalogy, 93: 1393-1404.

Hayman, R. W., and J. E. Hill. 1971. Order Chiroptera. Pp. 1-73, in The mammals of Africa: an identification manual (J. Meester and H. Setzer, eds.). Smithsonian Institution Press, Washington, D.C., 227 pp.

Hristov, N. I., M. BetKe, D. E. H. Theriault, A. Bagchi, and T. H. KUNZ. 2010. Seasonal variation in colony size of Brazilian free-tailed bats at Carlsbad Cavern based on thermal imaging. Journal of Mammalogy, 91: 183-192.

Juste, J., C. IBAÑEZ, and A. MACHORdOM. 2000. Morphological and allozyme variation of Eidolon helvum (Mammalia: Megachiroptera) in the islands of the Gulf of Guinea. Biological Journal of the Linnean Society, 71: 359-378.

Kamins, A. O., O. Restif, Y. Ntiamoa-Baidu, R. SuU-Ire, D. T. S. Hayman, A. A. Cunningham, J. L. N. Wood, and J. M. RowCLIFFE. 2011. Uncovering the fruit bat bushmeat commodity chain and the true extent of fruit bat hunting in Ghana, West Africa. Biological Conservation, 144: 3000-3008.

Kerth, G., N. Perony, and F. Schweitzer. 2011. Bats are able to maintain long-term social relationships despite the high fission-fusion dynamics of their groups. Proceedings of the Royal Society, 278B: 2761-2767.

KingDON, J. 1974. East African mammals: an atlas of evolution in Africa. Academic Press, London, 341 pp.

Kuzmin, I. V., M. Niezgoda, R. Franka, B. Agwanda, W. MarKotter, J. C. Beagley, O. Y. Urazova, R. F. Breiman, and C. E. RupPRECHT. 2008. Lagos bat virus in Kenya. Journal of Clinical Microbiology, 46: 1451-1461.

LANG, H., and J. P. Chapin. 1917a. Part II. Notes on the distribution and ecology of Central African Chiroptera. In The American Museum Congo expedition collection of bats (J. A. Allen, H. Lang, and J. P. Chapin). Bulletin of the American Museum of Natural History, 37: 479-496.

Lang, H., and J. P. Chapin. 1917b. Part III. Field notes. In The American Museum Congo expedition collection of bats ( $\mathrm{J}$. A. Allen, H. Lang, and J. P. Chapin, eds.). Bulletin of the American Museum of Natural History, 37: 497-563.

Markus, N., and L. HALl. 2004. Foraging behaviour of the black flying-fox (Pteropus alecto) in the urban landscape of Brisbane, Queensland. Journal of Wildlife Research, 31: 345-355.

McCracken, G. F., and G. S. Wilkinson. 2000. Bat mating systems. Pp. 321-362, in Reproductive biology of bats (E. G. CRICHTON and P. H. KRUTZSCH, eds.). Academic Press, New York, $510 \mathrm{pp}$.

Mickleburgh, S., A. M. Hutson, W. Bergmans, J. Fahr, and P. A. RACEY. 2008. Eidolon helvum. In IUCN 2008. 2008 IUCN Red List of Threatened Species. Available at www.iucnredlist.org. Downloaded on 6 February 2011. 
Mickleburgh, S., K. Waylen, and P. Racey. 2009. Bats as bushmeat: a global review. Oryx, 43: 217-234.

Mutere, F. A. 1965. Delayed implantation in an equatorial fruit bat. Nature, 207: 780 .

Mutere, F. A. 1967. The breeding biology of equatorial vertebrates; reproduction in the fruit bat E. helvum, at latitude $0^{\circ} 20^{\prime}$ N. Journal of Zoology (London), 153: 153-161.

Mutere, F. A. 1980. Eidolon helvum revisited. Pp. 145-150, in Proceedings of the Fifth International Bat Research Conference (D. E. WiLson and A. L. GARDNER, eds.). Texas Tech Press, Lubbock, Texas, 434 pp.

Niamien, M., B. Kadjo, N. D. Dago, I. Koné, and E. K. N'GoRAN. 2015. Initial data on poaching of Eidolon helvum (Kerr, 1792) Near-Threatened Species in Côte D'Ivoire, West Africa. European Journal of Scientific Research, 135: 219-227.

O'Shea, T. J., M. A. Bogan, and L. E. Ellison. 2003. Monitoring trends in bat populations of the United States and territories: status of the science and recommendations for the future. Wildlife Society Bulletin, 31: 16-29.

Peel, A. J., D. R. SArgan, K. S. Baker, D. T. S. Hayman, J. A. Barr, G. Crameri, R. SuU-Ire, C. C. Broder, T. Lembo, L.-F. WANG, et al. 2013. Continent-wide panmixia of an African fruit bat facilitates transmission of potentially zoonotic viruses. Nature Communications, 4: 3770.

Peel, A. J., K. S. Baker, D. T. S. Hayman, R. SuU-Ire, A. C. Breed, G.-C. Gembu, T. Lembo, A. Fernández Loras, D. R. SARGAN, A. R. FoOKs, et al. 2016. Bat trait, genetic and pathogen data from large-scale investigations of African fruit bats, Eidolon helvum. Scientific Data, 3: 160049.

Perpetra, A., and M. R. Kityo. 2009. Populations of Eidolon helvum in Kampala over 40 years. Tanzania Journal of Forestry and Nature Conservation, 79: 1-7.

Plowright, R. K., P. Foley, H. E. Field, A. P. Dobson, J. E. FOLEY, P. EBY, and P. DASZAK. 2011. Urban habituation, ecological connectivity and epidemic dampening: the emergence of Hendra virus from flying foxes (Pteropus spp.). Proceedings of the Royal Society, 278B: 3703-3712.

Plowright, R. K., P. Eby, P. J. Hudson, I. L. Smith, D. WestCott, W. L. Bryden, D. Middleton, P. A. Reid, R. A. MCFARLANe, G. MARTIN, et al. 2015. Ecological dynamics of emerging bat virus spillover. Proceedings of the Royal Society, 282B: 20142124.
R Core TeAm. 2014. R: a language and environment for statistical computing. Version 3.0. R Foundation for Statistical Computing, Vienna, Austria. Available at http://www. R-project.org/.

Richter, H. V., and G. S. Cumming. 2006. Food availability and annual migration of the straw-colored fruit bat (Eidolon helvum). Journal of Zoology (London), 268: 35-44.

Richter, H. V., and G. S. Cumming. 2008. First application of satellite telemetry to track African straw-coloured fruit bat migration. Journal of Zoology (London), 275: 172-176.

SAndercock, B. K., E. B. Nilsen, H. Brøseth, and H. C. PeDERSEN. 2011. Is hunting mortality additive or compensatory to natural mortality? Effects of experimental harvest on the survival and cause-specific mortality of willow ptarmigan. Journal of Animal Ecology, 80: 244-258.

Sikes, R. S., W. L. Gannon, and the Animal Care and Use Committee of the American Society of Mammalogists. 2011. Guidelines of the American Society of Mammalogists for the use of wild mammals in research. Journal of Mammalogy, 92: 235-253.

Sodeinde, O. A., and D. A. Soewu. 1999. Pilot study of the traditional medicine trade in Nigeria. Traffic Bulletin, 18: 35-40.

Storz, J. F., H. R. BHAT, and T. H. KunZ. 2000. Social structure of a polygynous tent-making bat, Cynopterus sphinx (Megachiroptera). Journal of Zoology (London), 251: 151-165.

Storz, J. F., H. R. Bhat, and T. H. KunZ. 2001. Genetic consequences of polygyny and social structure in an Indian fruit bat, Cynopterus sphinx. I. Inbreeding, outbreeding, and population subdivision. Evolution, 55: 1215-1223.

SuZUKI, T. 2010. Seasonal variation of the ITCZ and its characteristics over central Africa. Theoretical and Applied Climatology, 103: 39-60.

Westcott, D. A., and A. McKeown. 2004. Observer error in exit counts of flying-foxes (Pteropus spp.). Wildlife Research, 31: 551-558.

Williams, B. K., J. D. Nichols, and M. J. Conroy. 2002. Analysis and management of animal populations. Academic Press, San Diego, California, 817 pp.

Willis, C. K. R., and R. M. BRigham. 2004. Roost switching, roost sharing and social cohesion: forest-dwelling big brown bats, Eptesicus fuscus, conform to the fission-fusion model. Animal Behaviour, 68: 495-505.

Received 18 February 2016, accepted 24 April 2016

Associate Editor: Sébastien Puechmaille 